\title{
Knowledge and Attitude of University Students on Antibiotics: A Cross-sectional Study in Malaysia
}

This article was published in the following Dove Press journal:

Drug, Healthcare and Patient Safety

\section{Ting Wei Tiong}

Siew Siang Chua $(\mathbb{D}$

School of Pharmacy, Faculty of Health and Medical Sciences, Taylor's University, Subang Jaya, Selangor, Malaysia
Correspondence: Siew Siang Chua School of Pharmacy, Faculty of Health and Medical Sciences, Taylor's University, I Jalan Taylor's, Subang Jaya 47500, Selangor, Malaysia

Tel +6035629560I

Email siewsiang.chua@taylors.edu.my
Background: Antibiotic resistance has become one of the major global health threats. The lack of knowledge on antibiotics contributes to the indiscriminate use of these medications and subsequent antibiotic resistance.

Objective: To evaluate the knowledge and attitude of university students regarding antibiotics.

Methods: A cross-sectional study was conducted on university students at a private university in Malaysia in 2018, using a self-administered validated questionnaire.

Results: Of the 424 respondents included in this study, $25.7 \%$ had taken antibiotics in the previous month while $22.6 \%$ had good knowledge about antibiotics. The faculty to which the respondents were attached was the only determinant associated with the respondents' knowledge level on antibiotics. The odds of respondents from other faculties having poor knowledge level on antibiotics were significantly higher than those from the Faculty of Health and Medical Sciences $(P<0.001)$. The study found that $77.8 \%$ of the respondents knew the roles of antibiotics in treating bacterial infections, but only $27.4 \%$ knew that antibiotics were not for viral infections. However, $46.5 \%$ of the respondents recognized that penicillin is an antibiotic, but only $35.4 \%$ and $9.2 \%$ knew that aspirin and diphenhydramine, respectively, are not antibiotics. More than $70 \%$ of the respondents were aware that antibiotics have side effects and that overuse of antibiotics could lead to resistance. However, 35.6\% expected antibiotics to be prescribed for common colds and 33\% would not complete their course of antibiotics.

Conclusion: The study shows that university students do not have adequate knowledge and about one-third have misconceptions about antibiotics. This calls for health education interventions at university level as this target population will be the future leaders of the country.

Keywords: antibiotic, resistance, knowledge, attitude, university students

\section{Introduction}

The rapid development of antibiotic resistance has become one of the most serious global threats to public health as this can affect people of any age, in any country. Antibiotic resistance reduces the effectiveness of treatment for infectious diseases, resulting in higher medical costs, longer duration of illness, longer hospital stays, more intensive care as well as increases morbidity and mortality. ${ }^{1}$

Studies showed that the rise in antibiotic resistance was associated with the increase in antibiotic consumption, which could have been driven by inadequate patient education or irrational use of antibiotics. ${ }^{2}$ Based on the Malaysian Statistics on Medicine in 2014 , antibiotics were the 13 th most commonly utilised therapeutic 
group, with a total of $10.8702 \mathrm{DDD} / 1000$ inhabitants in both public and private health care, and accounted for the largest proportion of drug expenditure from year 2011 to $2014 .^{3}$ The prescribing rate for antibiotics was reported as $21.1 \%$ in private and public clinics, and upper respiratory tract infections accounted for $49.2 \%$ of the antibiotic prescriptions. Penicillin, cephalosporins and macrolides were the most commonly prescribed antibiotics, which accounted for $30.7 \%, 23.6 \%$ and $16 \%$ of the total antibiotic usage, respectively. ${ }^{4}$

The Malaysia National Surveillance on Antibiotics Resistance in 2016 reported an increase in antibiotic resistance for the common strains of bacteria such as Enterococcus faecium, Klebsiella pnuemoniae, Salmonella species, Staphylococcus sp. and Streptococcus pneumoniae in Malaysia. ${ }^{5}$ Antibiotic resistance is directly related to the knowledge and attitude of the general public on antibiotic use. Most of the studies found that the development of microbial resistance in patients who received antibiotics was contributed by patient non-compliance, the use of leftover antibiotics and sharing of medicines. ${ }^{6}$ In addition, almost $50 \%$ of antibiotics used in human and animals were inappropriate and unnecessary. ${ }^{7}$

Studies on university students' knowledge and attitude towards antibiotics vary with different geographical locations. ${ }^{8-14}$ Overall, the studies reported inadequate knowledge among students from non-health related programmes while those from health-related programmes had better understanding about antibiotics. However, students from health-related programmes showed poorer attitude towards the use of antibiotics. Thus far, in Malaysia, only studies on knowledge and attitude of the general public or patients towards the use of antibiotics had been reported. ${ }^{2,15-18}$

The main measure to minimise the development and increase in antibiotic resistance is to prevent the indiscriminate use of antibiotics. ${ }^{7}$ Educational programmes should be implemented to instill awareness on the appropriate use of antibiotics among health care providers as well as the general public. The types and extent of educational interventions will depend on the target population. Therefore, the present study was conducted to investigate the knowledge of university students on antibiotics as this population group would be leaders of tomorrow. The findings of this study would provide further insights for the designing of awareness campaigns or health education programmes to combat the inappropriate use of antibiotics and subsequently to curtail antimicrobial resistance.

\section{Methods}

\section{Study Design and Setting}

A cross-sectional study was conducted from September to December 2018 on undergraduate students of a major private university in Malaysia. Data was collected using a validated self-administered questionnaire. The study was reviewed and approved by the Taylor's University Human Ethics Committee (Ref. No. HEC 2018/039).

\section{Participants and Sample Size}

Included were university students aged 18 years and above; who could understand, read and write in English; were registered as an undergraduate in the university under study and had agreed to participate in the study. Those who declined to sign the informed consent form were excluded from the study.

The sample size for this study was calculated using Raosoft sample size calculator (http://www.raosoft.com/ samplesize.html). Based on a student population of more than 10,000 in the university, with a confidence level of $95 \%$, within $5 \%$ margin of error and assuming that $50 \%$ has good knowledge of antibiotics, a minimum sample size of 373 was required.

\section{Questionnaire}

Data was collected using a validated questionnaire from a previous study in Malaysia. ${ }^{18}$ The questionnaire was in English and comprised of four sections. The first section was to record demographic details of respondents while the second section was about the respondents' antibiotic consumption during the past one month and their sources of information. The third section consisted of 14 statements about antibiotics which included its roles, identification, adverse effects and use. This was to assess the respondents' knowledge on antibiotics. Respondents were asked to respond to each of the statements with either "Correct", "Incorrect" or "Unsure". The fourth section contained 8 statements to assess respondents' attitude towards the use of antibiotics and the responses consisted of a 5-point Likert-like scale which ranged from "strongly disagree" to "strongly agree".

\section{Pilot Study}

A pilot study was conducted on 30 university students to ensure that all the data needed to meet the objectives of the study could be collected with the questionnaire. In addition, the pilot study obtained feedback on the clarity of the 
questions and assessed the feasibility of the study protocol. No changes to the questionnaire were needed but results from the pilot study were excluded in the analysis of the main study.

\section{Data Collection Procedure}

A researcher was stationed at common areas of the university such as study areas near the library, outside lecture theatres and classrooms, areas in the commercial block (with shops and eateries) which were frequented by students. The researcher approached any students who were in these areas based on convenience sampling.

The researcher explained the objectives and procedure of the study to potential respondents and if they agreed to participate in the study, they were requested to sign an informed consent form. The researcher then gave a set of the questionnaire to the respondent for him/her to fill in. After the respondent had self-completed the questionnaire, the researcher collected it immediately. To ensure anonymity, no personal identifiers of the respondents were included in the questionnaire.

\section{Data Analysis}

All the data collected was entered into and analysed using the Statistical Package for the Social Science (SPSS), version 20.0 (Armonk, NY: IBM Corp.). Only completed questionnaires were included in the analysis. Descriptive statistics such as frequencies and percentages were generated for categorical variables while mean (standard deviations, SD) or median (interquartile range, IQR) were generated for numerical data.

To assess the knowledge of respondents on antibiotics, the knowledge level or score was determined by calculating the number of correct answers. Knowledge levels were categorised as poor ( $0-4$ correct answers), moderate (5-9 correct responses) and good (10-14 correct responses). ${ }^{18}$ Any association between the different knowledge levels and characteristics of respondents was determined using univariate Pearson chi square test followed by ordinal logistic regression using Generalized Linear Model (GLM) and regression analysis. Any p-value $<0.05$ was considered as statistically significant. To assess the attitude of respondents towards antibiotic use, responses of "strongly disagree" and "disagree" were combined as disagree while "strongly agree" and "agree" were classified as agree. ${ }^{18}$

\section{Results}

\section{Characteristics of Respondents}

A total of 432 university students were approached to participate in this study. However, 4 declined and 4 did not complete the questionnaires and hence, were excluded from the study. This gave a response rate of $98 \%$ and a final total of 424 respondents.

The characteristics of respondents are as shown in Table 1. More female than male students participated in the study $(63.2 \%$ versus $36.8 \%)$. The mean (standard deviation, SD) age of the respondents was 20.6 (1.5) years and ranged from 18 to 30 . A majority of the respondents were Chinese (71.7\%).

\section{Use of Antibiotics and Sources of Information About Antibiotics}

Out of the 424 respondents, $25.7 \%$ had taken antibiotics in the previous month, mainly for the treatment of fever (27.7\%), sore throat (17.9\%), cough (16.2\%) and common colds $(12.7 \%)$. Almost three quarters $(72.2 \%)$ of the respondents claimed that they have knowledge about antibiotics, but $38 \%$ of the respondents depended on medical doctors as the main source of information regarding antibiotics, while around 30\% sourced such information from school education, pharmacists, internet and family members (Figure 1).

\section{Knowledge About Antibiotics}

More than half of the respondents $(61.1 \%, n=261)$ had moderate knowledge level about antibiotics. Associations between the demographic characteristics of the respondents and their knowledge levels on antibiotics are as shown in Table 1. Univariate analysis using chi-square test showed that age group of respondents $(p=0.025)$, years of study $(p<0.001)$ and faculty of study $(p<0.001)$ were significantly associated with knowledge level of antibiotics. Students in the age group of 21-23 years old, studying in year 4 and from the Faculty of Health and Medical Sciences were found to have better knowledge of antibiotic use.

Further analysis using ordinal logistic regression found that only the faculty of study of the respondents remained significantly associated with the knowledge level on antibiotics. The odds of poor knowledge among respondents from the Faculty of Hospitality, Food and Leisure Management (FHFLM); Faculty of Arts and Social Sciences (FASS); Faculty of Built Environment, 
Table I Characteristics of Respondents and Association with Knowledge Level

\begin{tabular}{|c|c|c|c|c|c|}
\hline \multirow[t]{2}{*}{ Characteristics } & \multirow[t]{2}{*}{ Number $(n=424)$} & \multicolumn{3}{|c|}{ Knowledge Level } & \multirow{2}{*}{$\begin{array}{l}P \text { value } \\
\left(\chi^{2} \text { test }\right)\end{array}$} \\
\hline & & Poor (0-4) & Moderate (5-9) & Good $(10-14)$ & \\
\hline \multicolumn{6}{|l|}{ Gender } \\
\hline Male & $156(36.8 \%)$ & $19(12.2 \%)$ & 97 (62.2\%) & $40(25.6 \%)$ & 0.218 \\
\hline Female & $268(63.2 \%)$ & $48(17.9 \%)$ & $164(61.2 \%)$ & $56(20.9 \%)$ & \\
\hline \multicolumn{6}{|l|}{ Age } \\
\hline $18-20$ & $210(49.5 \%)$ & $40(19.0 \%)$ & $133(62.3 \%)$ & 37 (17.6\%) & $0.026 *$ \\
\hline $21-23$ & 205 (48.3\%) & 27 (13.2\%) & 121 (59.0\%) & 57 (27.8\%) & \\
\hline$>23^{a}$ & $9(2.1 \%)$ & & & & \\
\hline \multicolumn{6}{|l|}{ Ethnic } \\
\hline Malay & $56(13.2 \%)$ & $9(16.1 \%)$ & $32(57.1 \%)$ & $15(26.8 \%)$ & 0.396 \\
\hline Chinese & $304(71.7 \%)$ & $51(16.8 \%)$ & $191(62.8 \%)$ & $62(20.4 \%)$ & \\
\hline Indian & 48 (11.3\%) & $5(10.4 \%)$ & $28(58.3 \%)$ & 15 (3I.2\%) & \\
\hline Others $^{\mathrm{a}}$ & $16(3.8 \%)$ & & & & \\
\hline \multicolumn{6}{|l|}{ Years of study } \\
\hline Year I & $105(24.8 \%)$ & $20(19.0 \%)$ & $72(68.6 \%)$ & $13(12.4 \%)$ & $<0.00 I^{* *}$ \\
\hline Year 2 & $163(38.4 \%)$ & $28(17.2 \%)$ & 97 (59.5\%) & $38(23.3 \%)$ & \\
\hline Year 3 & $12 \mid(28.5 \%)$ & 15 (12.4\%) & $82(67.8 \%)$ & $24(19.8 \%)$ & \\
\hline Year 4 & $34(8.0 \%)$ & $4(11.8 \%)$ & $9(26.5 \%)$ & $21(61.8 \%)$ & \\
\hline Year $5^{\mathrm{a}}$ & I $(0.2 \%)$ & & & & \\
\hline \multicolumn{6}{|l|}{ Faculty of study } \\
\hline Arts \& Social Sciences & $6 \mathrm{I}(14.4 \%)$ & 7 (II.5\%) & 44 (72.1\%) & $10(16.4 \%)$ & $<0.00 I^{* *}$ \\
\hline Built Environment, Engineering, Technology and Design & $123(29.0 \%)$ & $17(13.8 \%)$ & $80(65.0 \%)$ & $24(21.1 \%)$ & \\
\hline Business and Law & $106(25.0 \%)$ & $26(24.5 \%)$ & $69(65.1 \%)$ & II (10.4\%) & \\
\hline Health \& Medical Sciences & $64(15.1 \%)$ & $0(0.0 \%)$ & $19(29.7 \%)$ & $45(70.3 \%)$ & \\
\hline Hospitality, Food \& Leisure Management & $70(16.5 \%)$ & 17 (24.3\%) & $49(70.0 \%)$ & $4(5.7 \%)$ & \\
\hline Overall & $424(100 \%)$ & $67(15.8 \%)$ & $261(61.6 \%)$ & $96(22.6 \%)$ & \\
\hline
\end{tabular}

Notes: $* P$ value $<0.05$; **P value $<0.01$. ${ }^{a}$ Excluded from the analysis: other ethnic groups included Iban, Melanau, Bidayuh, Dusun, Chinese-Indian, Sikh, Punjabi, Kadazan.

Engineering, Technology and Design (FBEETD); and Faculty of Business and Law (FBL) were significantly higher compared to those from the Faculty of Health and Medical Sciences (FHMS) [Table 2]. In addition, the test for parallel lines showed a p-value of 0.141 (that is, $>0.05$ ) and hence, the equal proportion assumption for the ordinal regression was met. The Goodness-of-fit test showed that the model fit was acceptable (Pearson's Chi-square = 225.412, $d f=214, \mathrm{p}=0.283)$ and the Nagelkerke's R-square value was 0.273 .

Table 3 shows the different statements about antibiotics. A majority of the respondents (77.8\%) knew that antibiotics are medicines that can kill bacteria. However, only $27.4 \%$ of the respondents knew that antibiotics were not indicated for viral infections. For the section on identification of antibiotics, $46.5 \%$ of the respondents recognised that penicillin is an antibiotic but only $35.4 \%$ and $9.2 \%$ knew that aspirin and diphenhydramine, respectively, are not antibiotics. More than $70 \%$ of the respondents were aware that antibiotics have side effects and that overuse of antibiotics could lead to resistance. In addition, $66.7 \%$ of the respondents knew that the full course of antibiotics should be completed even if their symptoms improved.

\section{Attitude About Antibiotic Usage}

The percentage of respondents with positive and negative attitude is as shown in Table 3. Generally, the respondents have positive attitude towards the use of antibiotics. Only a minority of the respondents $(<10 \%)$ would use leftover antibiotics, did not check its expiry date and did not take antibiotics according to instructions. In addition, $35.6 \%$ of the respondents expected antibiotics to be prescribed for common colds and $33.3 \%$ would stop taking antibiotics when they felt better. 


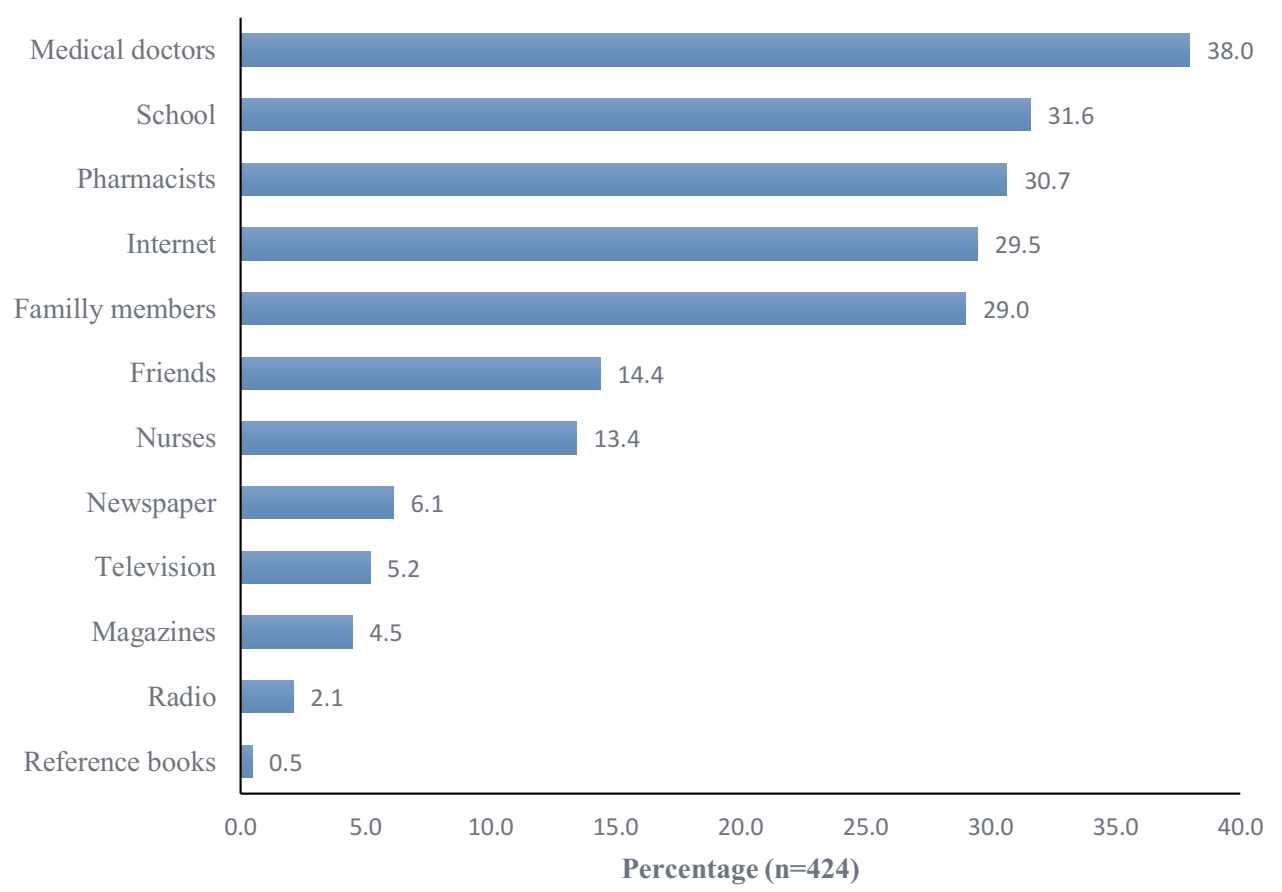

Figure I Sources of information about antibiotics.

Note: The percentages added up to more than $100 \%$ as each respondent could give more than one source of knowledge.

\section{Discussion}

\section{Characteristics of Respondents}

This study included almost equal proportions of respondents from all age groups except for those over 23 years old who only accounted for $2.1 \%$ of the total respondents. This is as expected since the target population are university students who are usually of similar age. There was also a higher proportion of Chinese students and this may be attributed to limited places in the public universities and generally, these students preferred private universities. The higher proportion of female students in this study was supported by the Malaysia Education Statistics 2017 which reported a higher percentage of female than male students in higher education institutions in Malaysia $(62.06 \%$ vs $37.94 \%) .{ }^{19}$

\section{Use of Antibiotics and Sources of Information About Antibiotics}

It was found that $25.7 \%$ of the respondents used antibiotics during the one-month period prior to the study. This proportion of respondents who took antibiotics is similar to that of an earlier study in Malaysia $(28.9 \%),{ }^{18}$ but the earlier study was conducted on a different target population (people around a hospital) and about 10 years ago. This implies that the use of antibiotics among university students can be considered quite high as this group of people are younger and hence, are presumably healthier than people who are in a hospital environment (majority were in the age group of 18 to 23 compared to over 30 years in the earlier study). However, the possibility that the respondents had mistaken the medications they took during the one-month prior to the study as antibiotics could not be ruled out.

It was observed that $38 \%$ of the respondents were dependent on medical doctors as the main source of information regarding antibiotics whilst about $30 \%$ sourced such information from school education, pharmacists, internet and family members. One of the contributing factors to the misconceptions about antibiotics may be unreliable sources of information such as people who shared their own experiences on antibiotic use through social media. Family members who are not health-care professionals may also provide incorrect information about antibiotics.

\section{Knowledge and Attitude About Antibiotic Use}

Of the 424 respondents, $22.6 \%$ had good knowledge about antibiotic use. Respondents from the Faculty of Health and Medical Sciences (FHMS) had significantly better knowledge than students from the other nonmedical faculties. This is in line with previous studies in China and 
Table 2 Possible Determinants of Knowledge Level on Antibiotics, from Ordinal Logistic Regression

\begin{tabular}{|c|c|c|c|c|c|c|c|c|c|c|}
\hline \multirow[t]{2}{*}{ Parameters } & \multirow[t]{2}{*}{ B } & \multirow[t]{2}{*}{ SE } & \multicolumn{2}{|c|}{ 95\% Wald Cl } & \multicolumn{3}{|c|}{ Hypothesis Test } & \multirow[t]{2}{*}{ OR } & \multicolumn{2}{|c|}{$95 \% \mathrm{Cl}$ for $\mathrm{OR}$} \\
\hline & & & Lower & Upper & Chi-squared & $d f$ & Sig. & & Lower & Upper \\
\hline Know $=$ Good & 2.288 & 0.8632 & 0.596 & 3.979 & 7.023 & I & 0.008 & 9.850 & 1.814 & $53.48 I$ \\
\hline Know $=$ Moderate & 5.749 & 0.9043 & 3.976 & 7.521 & 40.406 & I & 0.000 & 313.745 & 53.308 & 1846.547 \\
\hline FHFLM & 3.097 & 0.4230 & 2.268 & 3.926 & 53.593 & I & 0.000 & 22.132 & 9.659 & 50.713 \\
\hline FASS & 2.075 & 0.4231 & 1.246 & 2.904 & 24.052 & 1 & 0.000 & 7.964 & 3.475 & 18.250 \\
\hline FBEETD & 2.270 & 0.3753 & 1.534 & 3.006 & 36.574 & I & 0.000 & 9.679 & 4.638 & 20.199 \\
\hline $\mathrm{FBL}$ & 2.974 & 0.3934 & 2.203 & 3.745 & 57.167 & $\mathrm{I}$ & 0.000 & |9.57| & 9.053 & 42.310 \\
\hline FHMS & Ref & & & & & & & 1 & & \\
\hline Female & 0.351 & 0.2295 & -0.098 & 0.801 & 2.345 & $\mathrm{I}$ & 0.126 & 1.421 & 0.906 & 2.228 \\
\hline Male & Ref & & & & & & & 1 & & \\
\hline Age 18-23 & 0.770 & 0.7488 & -0.698 & 2.237 & 1.059 & I & 0.304 & 2.159 & 0.498 & 9.369 \\
\hline Age $21-23$ & 0.465 & 0.7227 & -0.952 & $1.88 \mid$ & 0.413 & I & 0.520 & $1.59 \mid$ & 0.386 & 6.561 \\
\hline Age $>23$ & Ref & & & & & & & 1 & & \\
\hline Chinese & 0.120 & 0.3225 & -0.512 & 0.752 & 0.139 & $\mathrm{I}$ & 0.710 & 1.128 & 0.599 & 2.122 \\
\hline Indian & 0.152 & 0.4322 & -0.695 & 0.999 & 0.124 & I & 0.725 & 1.164 & 0.499 & 2.716 \\
\hline Malay & Ref & & & & & & & 1 & & \\
\hline Year I & 0.735 & 0.5716 & -0.385 & 1.855 & 1.653 & $\mathrm{I}$ & 0.199 & 2.085 & 0.680 & 6.393 \\
\hline Year 2 & 0.580 & 0.4998 & -0.399 & 1.560 & 1.348 & I & 0.246 & 1.787 & 0.671 & 4.758 \\
\hline Year 3 & 0.703 & 0.4715 & -0.221 & 1.627 & 2.224 & I & 0.136 & 2.020 & 0.802 & 5.091 \\
\hline Year 4 & Ref & & & & & & & 1 & & \\
\hline Scale & 1 & & & & & & & & & \\
\hline
\end{tabular}

Note: Reference: Know = Poor.

Abbreviations: Know, knowledge level on antibiotics; B, coefficient; SE, standard error; Ref, reference group; FHFLM, Faculty of Hospitality, Food and Leisure Management; FASS, Faculty of Arts \& Social Sciences; FBEETD, Faculty of Built Environment, Engineering, Technology and Design; FBL, Faculty of Business and Law; FHMS, Faculty of Health and Medical Sciences.

Jordan. ${ }^{11,20}$ This may be because these students in the FHMS are mainly those with a science and health background and hence, had more exposure to scientific knowledge related to antibiotics compared to students from the other faculties. The proportion of respondents who had a moderate $(61.6 \%)$ and good $(22.6 \%)$ level of knowledge in this study were higher than the proportion of the general public who had a moderate $(54.7 \%)$ and good (16.4\%) level of knowledge reported in another study in Malaysia. ${ }^{8}$ This may be attributed to students from the Faculty of Health and Medical Sciences who had acquired health-related information through their education.

From the ordinal logistic regression, the main determinant of knowledge level on antibiotics was the faculty of study. Therefore, if there are limited resources, educational programs on antibiotics should be targeted at university students from programs that are nonscience based such as those from the Faculty of Hospitality, Food \& Leisure Management, and the Faculty of Business \& Law.

The results in Table 3 indicate that a considerable percentage $(51.4 \%)$ of the respondents misunderstood the effectiveness of antibiotics in treating viral infections. This is a cause for concern as antibiotics are not effective against viral infections such as influenza or the common cold, and fungal infections. ${ }^{21}$ Other studies in Malaysia ${ }^{2,6,15}$ and Nigeria $^{22}$ also reported high proportions of respondents (67.2-80\%) who thought that antibiotics were helpful for viral infections.

Such a misconception on the indication of antibiotics could lead to its misuse as shown in the present study where $19.9 \%, 16.2 \%$ and $12.7 \%$ of the respondents used antibiotics for treating sore throat, cough, and the common cold, respectively. It is important to know that sore throat and common colds are usually self-limiting and caused by viral infections and thus, antibiotic treatment may not be necessary. ${ }^{23,24}$ In addition, many respondents (35.6\%) expected doctors to prescribe antibiotics for the treatment of the common cold. However, the percentage in this study is lower compared to $68 \%$ reported by a study in India. ${ }^{12}$ Patients' incorrect expectations may lead to unnecessary or inappropriate prescribing and use of antibiotics. This is evidenced by a study which reported that $62 \%$ of the time the doctors would prescribe antibiotics if they thought that patients wanted them to do so, compared to $7 \%$ of the time 
Table 3 Knowledge and Attitude Towards Antibiotics

\begin{tabular}{|c|c|c|c|c|}
\hline & Knowledge Statement & $\begin{array}{l}\text { Correct Answer } \\
\text { Freq (\%) }\end{array}$ & $\begin{array}{l}\text { Incorrect Answer } \\
\text { Freq (\%) }\end{array}$ & $\begin{array}{l}\text { Unsure } \\
\text { Freq (\%) }\end{array}$ \\
\hline & \multicolumn{4}{|l|}{ Role of antibiotics } \\
\hline I. & Antibiotics are medicines that can kill bacteria. & $330(77.8)$ & $45(10.6)$ & $49(11.6)$ \\
\hline 2. & Antibiotics can be used to treat viral infections. & $116(27.4)$ & $218(51.4)$ & $90(21.2)$ \\
\hline 3. & Antibiotics can cure all infections. & $291(68.6)$ & $40(9.4)$ & $93(21.9)$ \\
\hline 4. & Antibiotics are indicated to relieve pain/inflammation. & $196(46.2)$ & $129(30.4)$ & $99(23.3)$ \\
\hline \multirow[t]{2}{*}{5.} & Antibiotics are used to stop fever. & I87 (44.I) & $148(34.9)$ & $89(21.0)$ \\
\hline & \multicolumn{4}{|l|}{ Identification of antibiotics } \\
\hline 6. & Penicillin is an antibiotic. & $197(46.5)$ & $45(10.6)$ & $182(42.9)$ \\
\hline 7. & Aspirin is a new generation of antibiotic. & $150(35.4)$ & 7I (I6.7) & $203(47.9)$ \\
\hline 8. & Paracetamol is considered as an antibiotic. & $175(4 \mid .3)$ & $96(22.6)$ & $153(36.1)$ \\
\hline \multirow[t]{2}{*}{9.} & Diphenhydramine is not an antibiotic. & $39(9.2)$ & $39(9.2)$ & $346(81.6)$ \\
\hline & \multicolumn{4}{|l|}{ Adverse effect of antibiotics } \\
\hline 10. & Overuse of antibiotics can cause antibiotic resistance. & 305 (7I.9) & $32(7.5)$ & $87(20.5)$ \\
\hline $\mathrm{II}$ & Antibiotics may cause allergic reaction. & $310(73.1)$ & $32(7.5)$ & $82(19.3)$ \\
\hline \multirow[t]{2}{*}{12.} & All antibiotics do not cause side effects. & $306(72.2)$ & $28(6.6)$ & $90(21.2)$ \\
\hline & \multicolumn{4}{|l|}{ Completion of treatment course } \\
\hline 13. & $\begin{array}{l}\text { You can stop taking a full course of antibiotic if your symptoms are } \\
\text { improving. }\end{array}$ & $283(66.7)$ & $72(17.0)$ & $69(16.3)$ \\
\hline \multirow[t]{2}{*}{14.} & $\begin{array}{l}\text { The effectiveness of treatment is reduced if a full course of antibiotic is } \\
\text { not completed. }\end{array}$ & $264(62.3)$ & $59(13.9)$ & I0I (23.8) \\
\hline & Attitude Statement & Agree & Disagree & Neutral \\
\hline $\mathrm{I}$. & When I get a cold, I will take antibiotics to help me get better more quickly. & $85(20.0)$ & $247(58.3)$ & $92(21.7)$ \\
\hline 2. & $\begin{array}{l}\text { I expect antibiotics to be prescribed by my doctor if I suffer from } \\
\text { common cold symptoms. }\end{array}$ & I5I (35.6) & $165(38.9)$ & $108(25.5)$ \\
\hline 3. & I normally stop taking antibiotics when I start feeling better. & $141(33.3)$ & $219(51.7)$ & $64(15.1)$ \\
\hline 4. & If my family member is sick, I usually will give my antibiotics to them. & $47(11.1)$ & $291(68.6)$ & $86(20.3)$ \\
\hline 5. & I normally keep antibiotics stocks at home in case of emergency. & $122(28.8)$ & $239(56.4)$ & $63(14.9)$ \\
\hline 6. & I will use leftover antibiotics for a respiratory illness. & $33(7.8)$ & $307(72.4)$ & $84(19.8)$ \\
\hline 7. & I will take antibiotics according to the instruction on the label. & $359(84.7)$ & $18(4.2)$ & $47(11.1)$ \\
\hline 8. & I normally will look at the expiry date of antibiotics before taking it. & $336(79.2)$ & $39(9.2)$ & $49(11.6)$ \\
\hline
\end{tabular}

Note: "Disagree" for attitude statement I-6 and "Agree" for attitude statement 7-8 are positive attitudes.

if doctors thought that patients did not. ${ }^{25}$ This indicates that the decision to prescribe antibiotics is greatly influenced by patients' opinion and doctors tend to try and meet patients' expectation even though the doctors know that it is not necessary. ${ }^{26}$

In the present study, the responses of "Unsure" were highest in the section on identification of antibiotics. A majority of the respondents lacked the knowledge of differences between antibiotics, anti-inflammatory and antipyretics, and antihistamines. More than $50 \%$ of the respondents did not know that penicillin is an antibiotic while aspirin and paracetamol which are so commonly used, are not antibiotics. Some possible reasons for such lack of knowledge are that students had never used or heard about these medicines before, they were more familiar with brand names instead of generic names or they rarely paid attention to the names of the medicines they used. $^{2}$

With regard to the administration of antibiotics, $66.7 \%$ of the respondents agreed that an antibiotic treatment course should be completed despite of improvement in symptoms. However, 51.7\% reported that they normally stopped taking antibiotics when they started to feel better. This shows that those with knowledge on the proper use of 
antibiotics do not necessarily follow it in practice. This is consistent with studies in other countries which demonstrated that a majority of health-care students had good knowledge but poor attitude towards the use of antibiotics. ${ }^{9,14}$ This incorrect attitude of not completing antibiotic treatment can contribute to the development of antibiotic resistance. Improvement in symptoms does not always necessarily mean that the infection has been completely eradicated and if the consumption of the antibiotic is stopped, the remaining bacteria may become resistant to the antibiotic. ${ }^{27}$ Studies among students in Jordan, Nigeria and Saudi Arabia reported slightly higher percentages (55$62.6 \%$ who did not complete their antibiotic treatment. $^{20,28,29}$ This is probably due to the incorrect assumption that the administration of antibiotics is similar to that of antipyretics or painkillers which could be stopped if the symptoms had subsided. ${ }^{2}$ The implementation of educational programs to emphasize on the consequences of such actions should be considered to prevent or minimize this misconception.

The majority of respondents $(>75 \%)$ used antibiotics according to instructions and checked the expiry date before taking them. Fewer respondents from this study stated that they would take antibiotics for cold symptoms (20\% vs $38 \%$ ), expected antibiotics to be prescribed if they had common colds (35.6\% vs $47.3 \%$ ) and did not complete a full course of treatment with the antibiotics (33.3\% vs 37\%) compared to a previous study in Malaysia. ${ }^{18}$ However, more respondents from this study agreed that they would keep antibiotics at home for future use (28.8\% vs $15 \%)$, use leftover antibiotics (7.8\% vs 3.2\%) and share antibiotics with sick family members $(11.1 \%$ vs $9.1 \%)$ than this previous study. ${ }^{18}$ Possible reasons for keeping antibiotics for future respiratory illness and using leftover antibiotics could be to save money on costly consultation fees and also it is not convenient to visit a doctor for minor illness. This is similar to a study in Malaysia where $64 \%$ of respondents did not consult a doctor for minor illness. ${ }^{16}$

\section{Limitations of the Study}

Firstly, the results obtained in this study were dependent on the recall ability and honesty of the respondents and hence, underreporting or overreporting could not be ruled out. Secondly, the generalizability of the results may be limited as it was conducted in only one private university in Malaysia and thus, the study population might not be representative of all university students in Malaysia. However, the results of this study indicate the need to provide health education at university level especially for students in nonscience programs.

The question set used in the present study is very broad and hence, future studies should consider the inclusion of more specific questions to examine attitudes towards antibiotic use and resistance.

\section{Conclusions}

This study showed that only $22.6 \%$ of students had good knowledge on the use of antibiotics. Students from the Faculty of Health and Medical Sciences had significantly better knowledge about antibiotics compared to students from other faculties. Nearly half of the respondents misunderstood the effectiveness of antibiotics in treating viral infections. In addition, several misconceptions regarding the use of antibiotics surfaced in this study, such as expectation of antibiotics to be prescribed for common colds, keeping antibiotics at home for future use, and stop taking antibiotics when symptoms improved. These indicate that the knowledge of antibiotics amongst university students is still lacking. Therefore, sustainable and well-planned health education programs which target at antibiotic-related misconceptions identified in this study, should be the main focus points for intervention to promote the prudent use of antibiotics.

\section{Summary}

Antibiotic resistance has become a major global health threat. The lack of knowledge on antibiotics contributes to the indiscriminate use of these medications and subsequently leads to antibiotic resistance. It is important that university students understand the risks of inappropriate antibiotic use as they will be the leaders of tomorrow and future policy makers of a country. The study found that university students lacked knowledge on antibiotics and about one-third of the students had misconceptions which may have the potential to cause or lead to antibiotic resistance. Therefore, the authorities concerned should consider the implementation of health education at university level.

\section{Acknowledgments}

We would like to express our gratitude to the people whose contributions made this research possible. We are indebted to the students who volunteered to participate in this study as it would not have been possible without them. We also like to thank Associate Professor Karuthan Chinna from the School of Medicine in Taylor's University for his assistance and advice on statistical analysis, and Mr Balachandran Naicker for editing the manuscript. 


\section{Disclosure}

The authors report no conflicts of interest in this work.

\section{References}

1. World Health Organization. Antibiotic resistance; 2018. Available from: http://www.who.int/news-room/fact-sheets/detail/antibioticresistance. Accessed November 7, 2018.

2. Lim KK, Teh CC. A cross sectional study of public knowledge and attitude towards antibiotics in Putrajaya, Malaysia. South Med Rev. 2012;5(2):26-33.

3. Ministry of Health Malaysia. Malaysia Statistics on Medicines 2011-2014; 2017. Available from https://www.pharmacy.gov.my/v2/ sites/default/files/document-upload/malaysian-statistics-medicines -2011-2014.pdf. Accessed November 7, 2018

4. Ab Rahman N, Teng CL, Sivasampu S. Antibiotic prescribing in public and private practice: A cross-sectional study in primary care clinics in Malaysia. BMC Infect Dis. 2016;16(1):1-8. doi:10.1186/ s12879-016-1530-2

5. Ministry of Health Malaysia. National Antibiotic Resistance Surveillance Report 2016. Institute for Medical Research; 2016.

6. Chandrakanth P, Mohamed Saleem TS, Reddy MM, Rao MM. Assessment of Public Knowledge and Attitude Regarding Antibiotic Use in a Tertiary Care Hospital. Asian J Pharm Clin Res. 2016;9 (1):118-122.

7. Center for Disease Control and Prevention. About Antimicrobial Resistance; 2018. Available from: https://www.cdc.gov/drugresis tance/about.html. Accessed November 9, 2018.

8. Lv B, Zhou Z, Xu G, et al. Knowledge, attitudes and practices concerning self-medication with antibiotics among university students in western China. Trop Med Int Health. 2014;19(7):769-779. doi:10.1111/tmi.12322

9. Dhingra S, Khan M, Maharaj S, Pandey S, Patel I, Ahmad A. Knowledge, attitude and practice of B.Sc. Pharmacy students about antibiotics in Trinidad and Tobago. J Res Pharm Pract. 2015;4 (1):37-41. doi:10.4103/2279-042X.150057

10. Dyar O, Hills H, Seitz L-T, Perry A, Ashiru-Oredope D. Assessing the Knowledge, Attitudes and Behaviors of Human and Animal Health Students towards Antibiotic Use and Resistance: A Pilot Cross-Sectional Study in the UK. Antibiotics. 2018;7(10):2-8. doi:10.3390/antibiotics7010010

11. Huang Y, Gu J, Zhang M, et al. Knowledge, attitude and practice of antibiotics: A questionnaire study among 2500 Chinese students. BMC Med Educ. 2013;13(1):1-9. doi:10.1186/1472-6920-13-163

12. Limaye D, Naware S, Bare $P$, et al. Knowledge, attitude and practices of antibiotic usage among students from Mumbai University. Int J Res Med Sci. 2018;6(6):1908-1912. doi:10.18203/2320-6012. ijrms 20182270

13. Mukharjee SK, Mahmud I, Akter S, Hossain S. Knowledge, Attitudes and Practices Regarding Antibiotic Use Among the Students of Microbiology Department At Noakhali Science and Technology University, Bangladesh. J Drug Deliv Ther. 2017;7(4):34-37.

14. Scaioli G, Gualano MR, Gili R, Masucci S, Bert F, Siliquini R. Antibiotic Use: A cross-sectional survey assessing the knowledge, attitudes and practices amongst students of a school of medicine in Italy. PLoS One. 2015;10(4):1-12. doi:10.1371/journal.pone.0122476
15. Al-Haddad MS. General public knowledge, source of knowledge and practice towards antibiotics in the state of Penang, Malaysia. Arch Pharm Pract. 2012;3(3):233-241. doi:10.4103/2045-080X.111890

16. Hassali MA, Arief M, Saleem F, et al. Assessment of attitudes and practices of young Malaysian adults about antibiotics use: A cross-sectional study. Pharm Pract. 2017;15(2):1-7.

17. Islahudin F, Madihah A, Tamezi A, Shah NM, Lumpur K. Knowledge, Attitudes and Practices About Antibiotic Use Among the General Public in Malaysia. Southeast Asian J Trop Med Public Health. 2012;45(6):2012.

18. Oh AL, Hassali MA, Al-Haddad MS, Sulaiman SAS, Shafie AA, Awaisu A. Public knowledge and attitudes towards antibiotic usage: A cross-sectional study among the general public in the state of Penang, Malaysia. J Infect Dev Ctries. 2011;5(5):338-347. doi: $10.3855 /$ jidc. 1502

19. Ministry of Education Malaysia. Quick Facts Malaysia Education Statistics; 2017:1-291

20. Suaifan GARY. A cross-sectional study on knowledge, attitude and behavior related to antibiotic use and resistance among medical and non-medical university students in Jordan. African $J$ Pharm Pharmacol. 2012;6(10):763-770.

21. Center for Disease Control and Prevention. Antibiotic Resistance Questions and Answers; 2015. Available from: https://www.cdc. gov/antibiotic-use/community/about/antibiotic-resistance-faqs.html. Accessed November 7, 2018.

22. Asogwa I, Offor S, Mbagwu H. Knowledge, Attitude and Practice towards Antibiotics Use among Non-medical University Students in Uyo, Nigeria. J Adv Med Pharm Sci. 2017;15(1):1-11.

23. Center for Disease Control and Prevention. Sore Throat; 2015. Available from: https://www.cdc.gov/antibiotic-use/community/forpatients/common-illnesses/sore-throat.html. Accessed November 10, 2018.

24. Center for Disease Control and Prevention. Common Cold and Runny Nose; 2017. Available from: https://www.cdc.gov/antibioticuse/community/for-patients/common-illnesses/colds.html. Accessed November 10, 2018.

25. Mangione-Smith R, McGlynn EA, Elliott MN, Krogstad P, Brook RH. The Relationship Between Perceived Parental Expectations and Pediatrician Antimicrobial Prescribing Behavior. Pediatrics. 1999;103:711-718. doi:10.1542/peds.103.4.711

26. Butler CC, Stephen R, Roisin P, Frances Maggs-Rapport NS. Understanding the culture of prescribing: qualitative study of general practitioners' and patients' perceptions of antibiotics for sore throats. BMJ. 1998;317(7159):637-642. doi:10.1136/bmj.317.7159.637

27. Office of the Commissioner. Consumer Updates - Combating Antibiotic Resistance. US Food and Drug Administration; 2011. Available from: https://www.fda.gov/ForConsumers/ ConsumerUpdates/ucm092810.htm. Accessed November 8, 2018.

28. Igbeneghu OA. Knowledge and practices in the use of antibiotics among a group of Nigerian university students. Int $J$ Infect Control. 2013;9(1):1-8. doi:10.3396/ijic.v9i1.007.13

29. Mostafa-hedeab G. Knowledge, attitude and behaviors toward antibiotics of non-medical students Jouf University, Saudi Arabia. Asian J Pharm Clin Res. 2018;11(8):294-299. doi:10.22159/ajpcr.2018. v11i8.26308 


\section{Publish your work in this journal}

Drug, Healthcare and Patient Safety is an international, peer-reviewed open-access journal exploring patient safety issues in the healthcare continuum from diagnostic and screening interventions through to treatment, drug therapy and surgery. The journal is characterized by the rapid reporting of reviews, original research, clinical, epidemiological and post-marketing surveillance studies, risk management, health literacy and educational programs across all areas of healthcare delivery. The manuscript management system is completely online and includes a very quick and fair peer-review system. Visit http://www.dovepress.com/testimonials.php to read real quotes from published authors. 